\title{
Aprendendo com leituras e textos: uma estratégia pedagógica para o ensino de Ciências da Natureza
}

\author{
Learning from readings and texts: a pedagogical strategy for the \\ teaching of Natural Sciences
}

\author{
Ricardo Ferreira Vale (ricardo.vale@aluno.ufop.edu.br) \\ Universidade Federal de Ouro Preto (UFOP)
}

Resumo: A leitura de um livro paradidático, qualquer que seja o livro, só fará sentido em sala de aula se ela estiver inserida dentro de um contexto maior, ou seja, a leitura de um livro paradidático somente se tornará um recurso pedagógico, se relacionado diretamente com o que está acontecendo no mundo do aluno. O presente trabalho tem por objetivo demonstrar o uso de uma "fábula" como recurso pedagógico para o ensino de parasitologia, contribuindo consequentemente para o desenvolvimento da prática de leitura e sua compreensão. Os sujeitos participantes foram 35 alunos do $6^{\circ}$ ano (Ensino Fundamental II) de uma escola pública do Estado de Minas Gerais. A fábula escolhida e utilizada para a atividade foi "O barbeiro e o tatu", do livro Fábulas Parasitológicas de Pedro Marcos Linardi, que aborda o protozoário Tripanosoma cruzi. Foi distribuída uma cópia da fábula para os alunos, a realização de uma leitura individual e posteriormente uma leitura coletiva. Logo após a leitura, foi requisitado aos alunos que os mesmos representassem por meio de desenhos a sua compreensão diante do texto. Os resultados apontam que os alunos se mostraram capazes de compreender a fábula por conseguirem expressar as situações relatadas na mesma através da confecção de ilustrações, criação de histórias em quadrinhos e produção de charges acerca da temática, especificamente o protozoário Tripanosoma cruzi.

Palavras-chave: Divulgação científica; Recurso didático; Fábula; Ensino de parasitologia.

\begin{abstract}
Reading other than academic books in the classroom will only be meaningful if this reading is inserted in a bigger context, that is, reading a non-academic book will be considered a pedagogical resource if it is directly related to what is happening in the student's world. This work aims at showing the use of a fable as a pedagogical tool for the teaching of parasitology, thus contributing for the development of the practice of reading and comprehension skills. Thirty-five sixth graders (Junior High School) of a public school in Minas Gerais took part of the study. The chosen fable was "The Bug and the armadillo" from the book Fábulas Parasitológicas by Pedro Marcos Linardi, once it addresses the Tipassonoma cruzi protozoan. Each student was given a copy of the fable and they were asked to individually read it. After that, there was a collective reading in the classroom, and they were asked to represent their comprehension through drawings. The results show the students were able to understand the fable once they could produce drawings, comics and cartoons related to the theme of the fable, specifically the Tripanossoma cruzi protozoan.
\end{abstract}

Keywords: Science communication; Didactic resource; Fable; Parasitology teaching. 


\section{O DESENVOLVIMENTO DA COMPETÊNCIA LEITURA}

A leitura é um ato valioso. O desenvolvimento de uma criança muitas vezes está associado a essa práxis. A prática de ler é uma forma de acesso a informações e, diante de tais informes, buscar melhorias para si próprios e para o mundo. Em seus estudos Abramovich (1995, p. 16) descreve as primeiras experiências de leitura de uma criança.

O primeiro contato da criança com um texto é feito oralmente, através da voz
da mãe, do pai ou dos avós, contando contos de fadas, trechos da Bíblia,
histórias inventadas (tendo a criança ou os pais como personagens), livros
atuais e curtinhos, poemas sonoros e outros mais... contados durante o dia -
numa tarde de chuva, ou estando todos soltos na grama, num feriado ou
domingo - ou num momento de aconchego, á noite, antes de dormir, a criança
se preparando para um sono gostoso e reparador, e para um sono rico,
embalado por uma voz amada.

Estimular o hábito da leitura poderá interferir positivamente no processo de aprendizagem da criança, trazendo diversos benefícios para o seu desenvolvimento intelectual e cognitivo.

A leitura possibilita à criança o desenvolvimento de todos os aspectos necessários ao aprendizado na escola e em seu cotidiano. No entanto, é preciso que a prática de leitura vá além do conhecimento do alfabeto e da codificação e decodificação de palavras escritas. Corroborando, em seus estudos Rojo e Moura (2019, p. 15) nos afirmam que "isso ocorre, entre outras coisas, porque a leitura e compreensão de instruções simples, escritas passaram a ser requeridas pelas situações de trabalho na indústria e na vida das cidades".

Quanto mais lemos mais adquirimos o conhecimento permitindo e favorecendo uma ampliação na visão de mundo. Através da leitura a criança viaja, conhece outras culturas, se emociona, participa ativamente da situação proposta e sorri. Em seus estudos, Rossini (2003) mostra o quanto a educação está ligada à emoção, à motivação, ao bemestar da criança.

Quantos de nós, adultos, ao lermos conhecemos locais que nunca fomos? Por isso podemos dizer que a leitura é uma viagem sem sair do local, e em tal processo necessitamos somente da imaginação. As possibilidades de aprendizagem através da leitura são infinitas, portanto ela não deve ser unicamente caracterizada como um processo de decodificação de palavras.

A literatura deve ser vista como um processo interno e inteiro na aprendizagem, talvez o mais completo método de aprendizagem do ser humano. Em seus estudos Zismann, Bach e Wenzel (2019) apontam a prática de leitura como primordial no 
processo de ensino, visto que permite a expansão imaginária, criatividade, comunicação e posicionamento crítico frente ao texto. $\mathrm{O}$ que poderá interferir na compreensão e desenvolvimento nas demais disciplinas e não exclusivamente da língua materna.

\begin{abstract}
Ainda existe na comunidade escolar a cultura de que a formação do aluno leitor é de responsabilidade dos professores das séries iniciais e de Língua Portuguesa e Literatura, quando, na realidade, os níveis e os processos de leitura não caminham uma só direção, nem para uma área do saber. Se nossos professores compartilhassem entre si o conhecimento das teorias e das práticas de leitura, o processo ensino-aprendizagem da comunidade escolar conheceria, sem dúvida, momentos de profícuas discussões e de comprometimento coletivo (BRETAS, 2012, p. 25).
\end{abstract}

Uma estratégia pedagógica que pode favorecer a alfabetização é o uso de obras literárias em sala de aula. Porém, essa estratégia não tem sido executada por falta de conhecimento ou embasamento teórico dos professores do Ensino Fundamental II, no tocante à seleção de obras literárias cuja transversalidade contemple tanto a alfabetização da língua materna, quanto à alfabetização científica e as demais alfabetizações de áreas de conhecimento específicas.

\title{
2. A BASE NACIONAL COMUM CURRICULAR E A APLICAÇÃO DOS LETRAMENTOS
}

A Base Nacional Comum Curricular (BNCC) (BRASIL, 2017) propõe uma ampliação em relação aos letramentos tradicionalmente considerados pela escola. O que a escola costuma levar em conta, na maioria dos casos, são os chamados letramentos de letra, pensando nas regras do bem falar e do bem escrever.

Segundo Soares (2009), o termo letramento surgiu em 1980 como verdadeira condição para a sobrevivência e conquista da cidadania, no contexto das transformações culturais, sociais, políticas, econômicas e tecnológicas. Ampliou-se assim o conhecimento do que tradicionalmente se conhecia por alfabetização.

Em convergência com o exposto, Solé (1998) nos diz que a escola ensina a ler e não propõe tarefas para que os alunos pratiquem essa competência. Ainda não se acredita completamente na ideia de que isso deve ser feito não apenas no início da escolarização, mas num processo contínuo, a fim de que os educandos deem conta dos textos imprescindíveis para a realização das novas exigências que vão surgindo ao longo do tempo. Considera-se que a leitura é uma habilidade que, uma vez adquirida pelos alunos, pode ser aplicada sem problemas a múltiplos textos. 
Os objetos de conhecimentos e as habilidades expressas na BNCC para componente curricular Ciências da Natureza no Ensino Fundamental II, são detalhados no Quadro 1.

Quadro 1 - Competências gerais da BNCC.

\begin{tabular}{|c|c|}
\hline 1 & $\begin{array}{l}\text { Valorizar e utilizar os conhecimentos historicamente construídos sobre o } \\
\text { mundo físico, social, cultural e digital para entender e explicar a realidade, } \\
\text { continuar aprendendo e colaborar para a construção de uma sociedade justa, } \\
\text { democrática e inclusiva. }\end{array}$ \\
\hline 2 & $\begin{array}{l}\text { ercitar a curiosidade intelectual e recorrer à abordagem própria das ciências, } \\
\text { luindo a investigação, a reflexão, a análise crítica, a imaginação e a } \\
\text { atividade, para investigar causas, elaborar e testar hipóteses, formular e } \\
\text { solver problemas e criar soluções (inclusive tecnológicas) com base nos } \\
\text { nhecimentos das diferentes áreas. }\end{array}$ \\
\hline 3 & $\begin{array}{l}\text { lorizar e fruir as diversas manifestações artísticas e culturais, das locais às } \\
\text { ndiais, e também participar de práticas diversificadas da produção artístico- } \\
\text { tural. }\end{array}$ \\
\hline 4 & $\begin{array}{l}\text { ilizar diferentes linguagens - verbal (oral ou visual-motora, como Libras, e } \\
\text { crita), corporal, visual, sonora e digital -, bem como conhecimentos das }\end{array}$ \\
\hline & $\begin{array}{l}\text { linguagens artística, matemática e científica, para se expressar e partilhar } \\
\text { informações, experiências, ideias e sentimentos em diferentes contextos e } \\
\text { produzir sentidos que levem ao entendimento mútuo. }\end{array}$ \\
\hline 5 & $\begin{array}{l}\text { criar tecnologias digitais de informação e comunicação } \\
\text { ficativa, reflexiva e ética nas diversas práticas sociais } \\
\text { para se comunicar, acessar e disseminar informações, } \\
\text { s, resolver problemas e exercer protagonismo e autoria } \\
\text { va. }\end{array}$ \\
\hline 6 & $\begin{array}{l}\text { Valorizar a diversidade de saberes e vivências culturais e apropriar-se de } \\
\text { conhecimentos e experiências que lhe possibilitem entender as relações próprias }\end{array}$ \\
\hline & $\begin{array}{l}\text { do mundo do trabalho e fazer escolhas alinhadas ao exercício da cidadania e ao } \\
\text { seu projeto de vida, com liberdade, autonomia, consciência crítica e } \\
\text { responsabilidade. }\end{array}$ \\
\hline 7 & $\begin{array}{l}\text { ar com base em fatos, dados e informaçõ } \\
\text { defender ideias, pontos de vista e decis } \\
\text { os direitos humanos, a consciência s } \\
\text { em âmbito local, regional e global, cc }\end{array}$ \\
\hline 8 & $\begin{array}{l}\text { Conhecer-se, apreciar-se e cuidar de sua saúde física e emocional, } \\
\text { compreendendo-se na diversidade humana e reconhecendo suas emoções e as } \\
\text { dos outros, com autocrítica e capacidade para lidar com elas. }\end{array}$ \\
\hline 9 & $\begin{array}{l}\text { Exercitar a empatia, o diálogo, a resolução de conflitos e a cooperação, fazendo- } \\
\text { se respeitar e promovendo o respeito ao outro e aos direitos humanos, com } \\
\text { acolhimento e valorização da diversidade de indivíduos e de grupos sociais, } \\
\text { seus saberes, identidades, culturas e potencialidades, sem preconceitos de } \\
\text { qualquer natureza. }\end{array}$ \\
\hline 10 & $\begin{array}{l}\text { Agir pessoal e coletivamente com autonomia, responsabilidade, flexibilidade, } \\
\text { resiliência e determinação, tomando decisões com base em princípios éticos, } \\
\text { democráticos, inclusivos, sustentáveis e solidários }\end{array}$ \\
\hline
\end{tabular}

Fonte: Elaborado pelo autor (2020) 
A BNCC contempla a ampliação dos tipos de letramento, agregando também a questão dos textos que envolvam imagem, imagens estáticas, imagens em movimento e imagem sonora. Na busca de compreendermos o termo letramento, tomamos o conceito em Santos (2007, p. 480):

[...] o letramento dos cidadãos vai desde o letramento no sentido de entendimento de princípios básicos de fenômenos no cotidiano até a capacidade de tomada de decisão em questões relativas à ciência e tecnologia em que estejam diretamente envolvidos, sejam decisões pessoais ou de interesse público.

Em seus estudos, Cope e Kalantzis (2000) consideram que a missão da educação é garantir que o indivíduo participe plenamente da vida pública, comunitária e econômica levando em consideração as diferenças culturais.

[...] a necessidade de a escola, em nome de uma nova ética e uma nova estética, considerar multimodalidade e a diversidade cultural dos povos da sociedade atual, no espaço escolar, a fim de construir propostas de ensino e aprendizagem que contemplem a linguagem interativa, transgressiva, híbrida, colaborativa, fronteiriça, mestiça (MILL, 2018, p. 465).

Saber ler é mais do que ser capaz de decodificar símbolos ou identificar letras e sílabas. Saber ler pressupõe dominar a linguagem em um nível que permita a modificação do próprio universo por meio dela. Quando aprendemos a ler um texto aprendemos a ler o mundo. Os analfabetos absolutos, os analfabetos funcionais, os não letrados estão fadados a ver o mundo com os olhos dos outros. O risco é ser enganado pela miopia alheia, seja ela causada por ignorância ou por má-fé e interesse escuso. Ajudando alguém a aprender a ler estaremos salvando uma alma da escuridão da dependência.

\section{PERCURSOS METODOLÓGICOS}

Os textos paradidáticos são caracterizados como uma leitura de maior tamanho. A leitura do paradidático pode ser um instrumento muito eficiente, se bem utilizado, para trabalhar a questão da motivação do aluno e da própria melhoria do desenvolvimento da habilidade de leitura na criança. De acordo com Zambona (1991, p. 3), as editoras oferecem às escolas dois tipos de livros, os didáticos e os paradidáticos.

Os paradidáticos são colocados no mercado com a finalidade de completar os didáticos, contribuindo com o trabalho do professor e promovendo ao mesmo e aos alunos novas abordagens acerca das temáticas estudadas. Na mesma direção, Colpo (2019, p.49) nos diz que:

[...] para mim tinham uma linguagem acessível, contemplavam aspectos da evolução da Ciência e traziam aspectos da construção do conhecimento científico que os textos que eu estava acostumada a ler (livro didático), não 
traziam.

Os sujeitos participantes do estudo foram 35 alunos do $6^{\circ}$ ano do Ensino Fundamental II de uma escola da rede pública de ensino, localizada na cidade de Sete Lagoas -MG.

O desenvolvimento da atividade foi realizado em quatro momentos: levantamento de obras paradidáticas infantojuvenis acerca da temática parasitologia, seleção do capítulo a ser trabalhado, leitura da fábula junto aos alunos, construção de desenhos acerca da interpretação da fábula.

$1^{\circ}$ momento - foi realizado um levantamento bibliográfico de obras literárias infantojuvenis que abordassem a temática parasitologia em cenários, atos e personagens. Sendo assim, foi selecionado o livro "Fábulas Parasitológicas" de Pedro Marcos Linardi (1998). A obra busca ensinar aos leitores curiosidades acerca da parasitologia. Com uma linguagem simples, o propósito dessas "fábulas" é tornar a parasitologia mais atraente e de mais fácil compreensão para alunos iniciantes e leigos.

Segundo Massaud Moisés (1988, p. 141) fábula é uma

Narrativa curta, não raro identificada com o apólogo e a parábola, em razão da moral, implícita ou explicita, que deve encerrar, e de sua estrutura dramática. No geral, é protagonizada por animais irracionais, cujo comportamento, preservando as características próprias, deixa transparecer uma alusão, via de regra satírica ou pedagógica, aos seres humanos. Escrita em versos até o século XVIII, em seguida adotou a prosa como veículo de expressão. De longeva original, talvez oriental, a fábula foi cultivada superiormente na Antiguidade clássica por Esopo, escravo grego do século VI a.C., e por Fedro, escritor latino do século I da era cristã. Modernamente, La Fontaine destaca-se como o mais importante dos fabulistas: suas histórias, dadas a lume entre 1668 e 1694, foram largamente traduzidas, aplaudidas e imitadas.

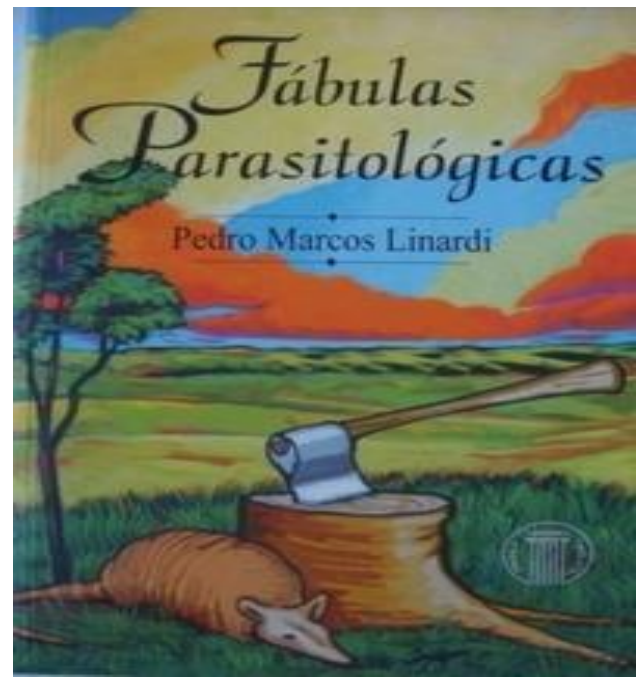

Figura 1- A obra literária selecionada "Fábulas Parasitológicas"

Fonte: Capa do livro "Fábulas Parasitólógicas" Editora Atheney, 1998. 
$2^{\circ}$ momento - O livro indicado introduz o conceito das principais doenças parasitológicas, agente etiológico, modo de transmissão e diagnóstico. A fábula selecionada para o trabalho foi "O barbeiro e o tatu". Ela busca ensinar aos leitores curiosidades sobre o tatu-hospedeiro, natural do parasita Tripanosoma cruzi, causador da doença de Chagas e o barbeiro como transmissor da doença ao homem.
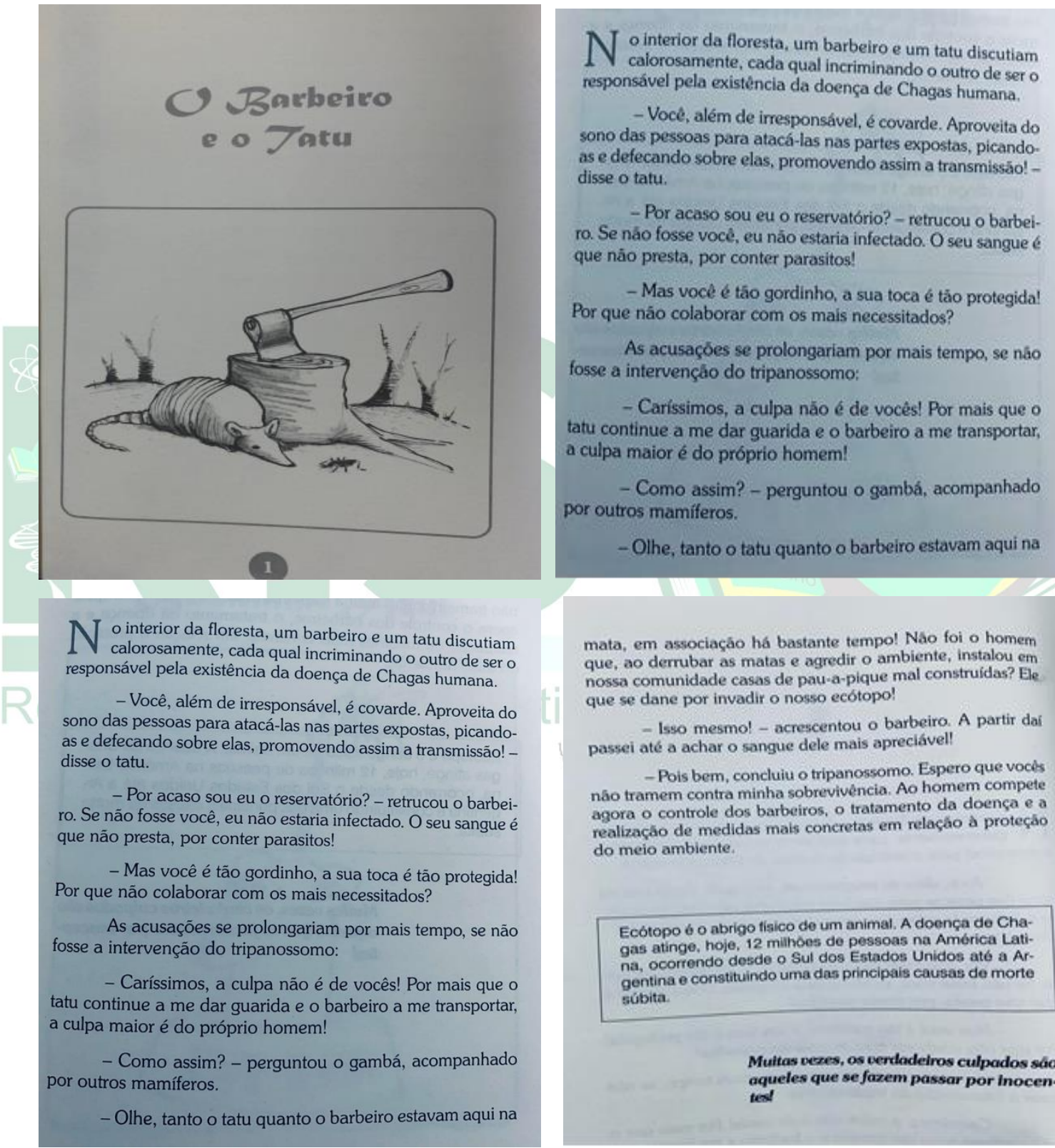

mata, em associaçâo há bastante tempo! Năo foi o homem que, ao derrubar as matas e agredir o ambiente, instalou $\mathrm{em}$ nossa comunidade casas de pau-a-pique mal construidas? Ele que se dane por invadir o nosso ecótopo!

- Isso mesmol - acrescentou o barbeiro. A partir daí passei até a achar o sangue dele mais apreciável!

- Pois bem, concluiu o tripanossomo. Espero que vocés náo tramem contra minha sobrevivéncia. Ao homem compete agora o controle dos barbeiros, o tratamento da doença e a realizaçáo de medidas mais concretas em relaçáo à proteçá do meio ambiente.

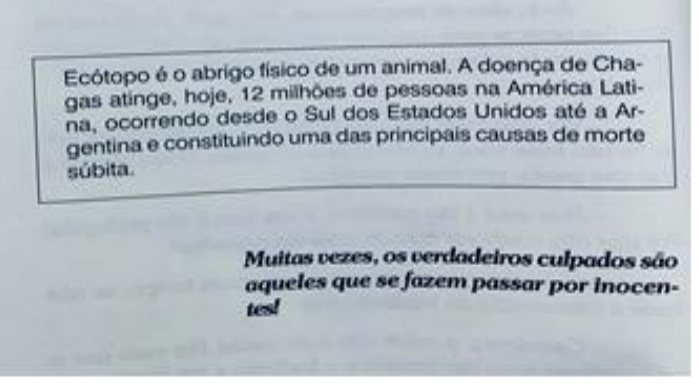

Figura 2- A fábula "O barbeiro e o tatu"

Fonte: Livro "Fábulas Parasitólógicas” Editora Atheney, 1998, p. 1,2,3 e 4

$3^{\circ}$ momento - Foi distribuída uma cópia da fábula para os alunos, a realização da leitura individual e, posteriormente, a leitura coletiva. 


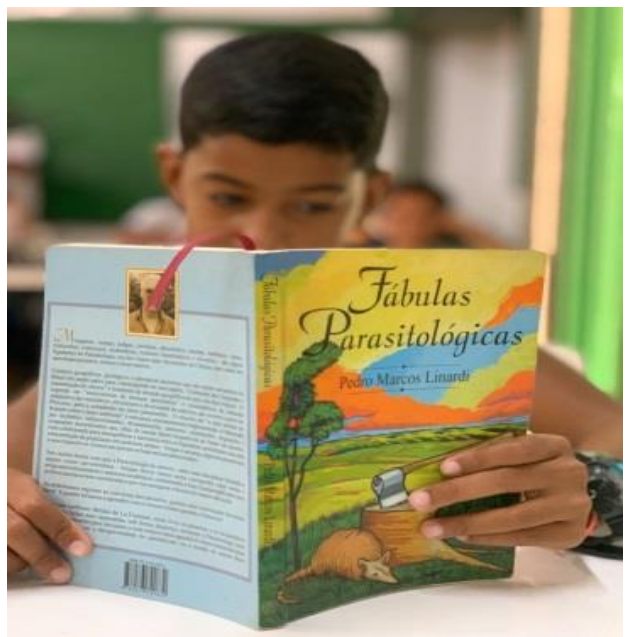

Figura 3: Leitura da fábula "O barbeiro e o tatu"

Fonte: Acervo pessoal do autor (2020)

$4^{\circ}$ momento - Após a leitura foi solicitado aos alunos que representassem por meio de desenhos sua compreensão, relacionada à fábula.

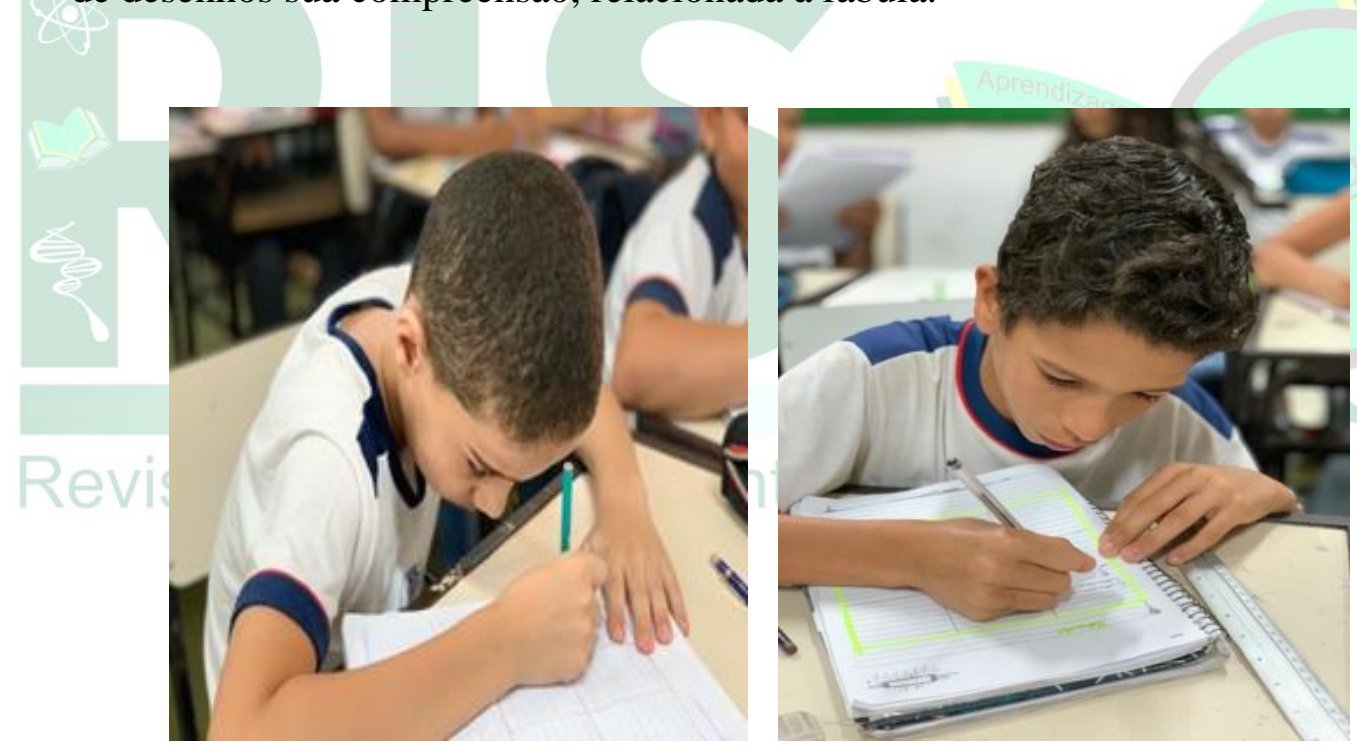

Figura 4: Construção de desenhos acerca da fábula "O barbeiro e o tatu"

Fonte: Acervo pessoal do autor (2020)

A educação em saúde no controle das parasitoses tem se mostrado uma estratégia com baixo custo, capaz de atingir resultados significativos e duradouros. As atividades de leitura, como facilitadoras da aprendizagem, favorecem um ambiente mais dinâmico, com participação dos alunos de forma mais ativa, favorecendo a argumentação e interação entre alunos e professor.

\section{RESULTADOS E DISCUSSÃO}


Os resultados apontam que os alunos se mostraram capazes de compreender a fábula, por expressarem situações relatadas no texto, principalmente na questão do reservatório natural do Tripanosoma cruzi, desmatamento de matas, casas de pau-a-pique e o barbeiro como transmissor do tripanossomo. Tornou-se perceptível que o uso da fábula como estratégia pedagógica para o ensino de parasitologia, contribuiu de forma significativa para compreensão e representação do saber científico, estimulando nos alunos à prática da leitura e o desenvolvimento das habilidades de representação visual e artística. Como instrumento de análise dos resultados foi realizada a leitura de imagens. Como nos diz Santos e Silva (2018, p. 4):

A leitura da imagem na cultura visual expressa uma representação da realidade, requerendo múltiplas fontes de conhecimento, o despertar de esquemas mentais, para a produção de significados, estimulando e direcionando a elaboração de outros. Desse modo, as condições de produção do sistema visual/imagem, bem como o contexto no qual se insere o leitor da imagem influenciam diretamente na compreensão, análise, reflexão e criação de sentidos, limitando sua apreensão ou expandido seus significados.

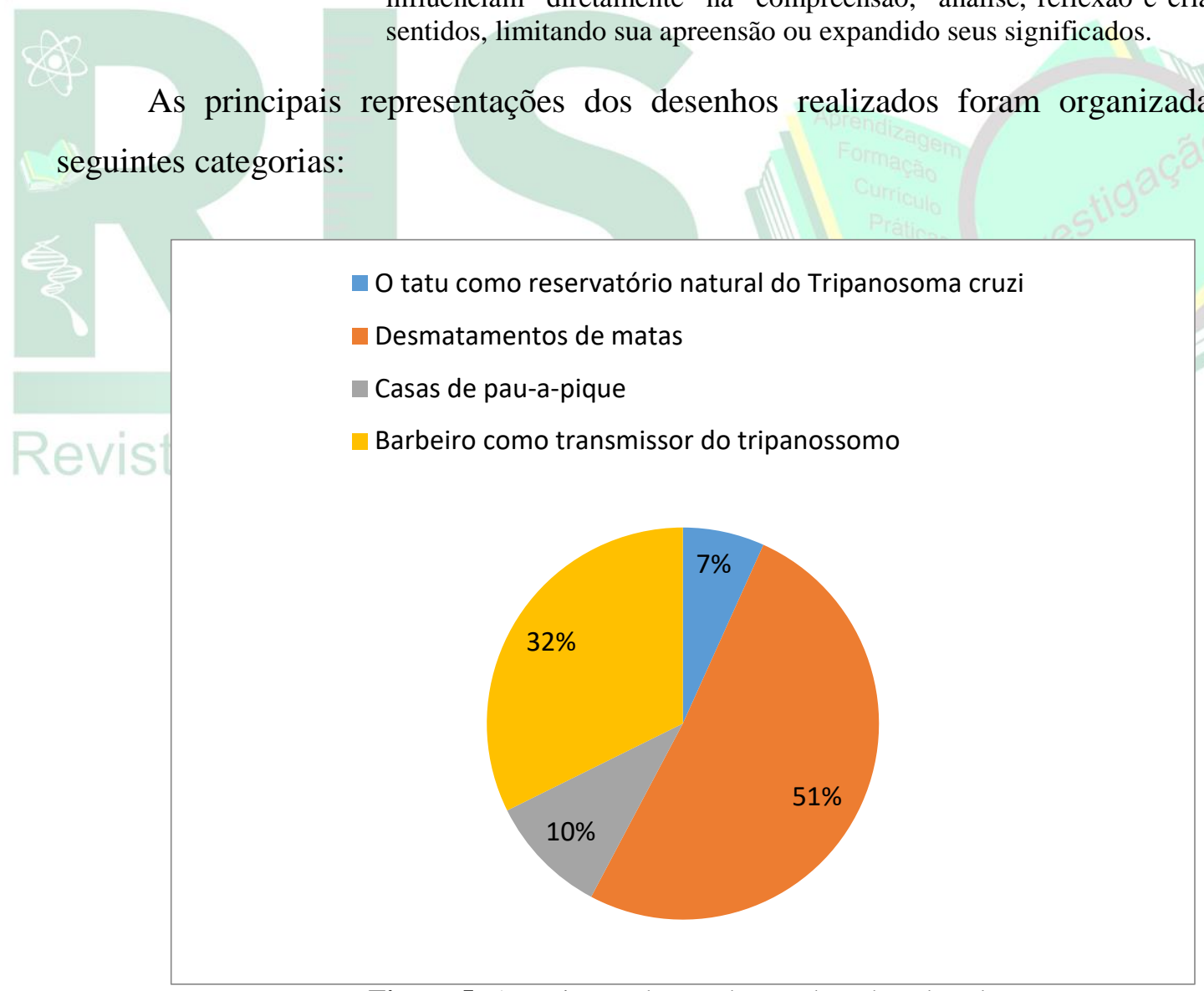

Figura 5: Associação observado nos desenhos dos alunos

Fonte: Dados interpretados pelo professor

A leitura de um texto, qualquer que seja, só fará sentido em sala de aula se ela estiver inserida dentro de um contexto maior. Ou seja, a leitura somente se tornará uma 
estratégia pedagógica, se ela tiver uma ligação direta com o que está acontecendo no mundo do aluno. Dessa maneira que o aluno conseguirá fazer ligações com o que acontece no mundo real e aquilo que está acontecendo em sala de aula.

No entanto, é preciso avançar nessa questão e superá-la, como analisa Freire (1989), concebendo a leitura como produção de sentidos realizada a partir de elementos textuais e contextos no discurso. A leitura é considerada um instrumento libertador das práticas sociais dominantes e sua função é também a de desvelar o reducionismo existente na instituição escolar e na sociedade, que concebe o texto como propagador de ideias.

Dessa perspectiva, ao valorizar apenas a linguagem verbal e a escrita em detrimento das outras formas de linguagem com as quais o leitor está em contato, a escola não permite a interação dessas formas de linguagem consideradas não legítimas, valorizando apenas o que o aluno lê no ambiente escolar, e nunca o que lê fora dele. A escola não incorpora em suas práticas pedagógicas outros tipos de linguagem e de leitura produzidos pelos indivíduos ao longo de sua história como leitores.

\section{CONSIDERAÇÕES FINAIS}

O estudo acerca da temática através de uma fábula e a posterior transformação da mesma em imagens possibilita ao aluno compreender e interpretar o que está acontecendo naquela situação e uma sequência de imagens é uma sequência de histórias que estão sendo contadas.

Através da leitura de imagens produzidas pelos próprios alunos os mesmos serão capazes de levantar hipóteses, que posteriormente poderão ser confirmadas ou não. Hipóteses tais como: O que aconteceu? Quais são os personagens? Que lugares foram mostrados? .

Qualquer que seja o livro paradidático, a seleção de tal deve ser feita tendo em mente a possibilidade de estabelecer uma relação com algum aspecto do contexto social em que o aluno está inserido.

O professor não deve somente indicar, mas sim fazer um trabalho de preparação em que se coloque inicialmente uma conversa sobre o contexto do livro paradidático e a leitura do mesmo pode ser feita em sala de aula ocupando pequenos períodos de 10 a 15 minutos por aula ao invés de ser estabelecida uma leitura única e exclusivamente em casa, diluindo, portanto, as leituras durante um espaço de tempo maior. 
E em cada espaço de tempo de leitura o professor pode elaborar atividades que auxiliem na compreensão da mesma favorecendo, portanto, que o aluno construa seus próprios instrumentos de estudos.

\section{REFERÊNCIAS}

ABRAMOVICH, Fanny. Literatura Infantil, gostosuras e bobices. São Paulo:

Scipione, 1995.

BRASIL. Ministério da Educação. Base Nacional Comum Curricular - Educação é a base. Disponível em:

http://portal.mec.gov.br/index.php?option=com_docman\&view=download\&alias=7960 1-anexo-texto-bncc-reexportado-pdf-2\&category_slug=dezembro-2017-

pdf\&Itemid=30192. Acesso em 18 mar. 2020.

BRETAS, Maria Luíza Batista. Leitura é fundamental: desafios na formação de jovens leitores. Belo Horizonte: RHJ, 2012.

COLPO, C. C. Estratégias de leitura de Textos de Divulgação Científica e a constituição docente de uma Professora de Química. Revista Insignare Scientia - RIS, v. 2, n. 3, p. 48- 55, 2019.

COPE, Bill and KALANTZIS, Mary (Ed). Multiliteracies: Literacy learning and the design of social futures. London and New York, Routledge, 2000.

FREIRE, Paulo. A importância do ato de ler: em três artigos que se completam. São Paulo: Autores Associados: Cortez, 1989.

LINARDI, Pedro Marques. Fábulas parasitológicas. São Paulo: Editora Atheney, 1998.

MOISÉS, Massaud. Dicionário de termos literários. São Paulo: Cultrix, 1988.

MILL, Daniel. Dicionário crítico de Educação e Tecnologias e de EAD. Campinas: Papirus, 2018.

ROJO, Roxane Helena; MOURA, Eduardo. Letramentos, mídias, linguagens. São

Paulo: Parábola Editorial, 2019.

ROSSINI, Maria Augusta Sanches. Aprender tem que ser gostoso.... Petrópolis:

Vozes, 2003. 
SANTOS, Wildson L.P. dos Santos. Educação científica na perspectiva de letramento como prática social: funções, princípios e desafios. Revista Brasileira de Educação, Rio de Janeiro, v. 12, n.36, set/dez. 2007. Disponível em: http://www.scielo.br/scielo.php?script=sci_arttext\&pid=S1413-24782007000300007. Acesso em: 18 mar. 2020.

SANTOS, Kassius Augusto Morais dos; SILVA, Daniele Cariolano da. Leitura imagética e a formação docente: algumas ponderações. Didática e Prática de Ensino na relação com a Escola. In: Livro 1, EdUECE, S.1. S.d. Disponível em: http://www.uece.br/endipe2014/index.php/2015-02-26-14-09-14?limit=5\&start=1110. Acesso em: 18 mar. 2020.

SOARES, Magda. Letramento: um tema em três gêneros. Belo Horizonte: Autêntica Editora, 2009.

SOLÉ, Izabel. Estratégias de leitura. Porto Alegre: Editora Artmed, 1998.

ZAMBONA, Ernesta. Que história é essa? - uma proposta do livro analítica dos livros paradidáticos de História. Tese de doutorado - Universidade Estadual de Campinas, São Paulo, 1991.

ZISMANN, Jonatan Josias; BACH, Sabrina Thais; WENZEL, Judite Scherer. A leitura de texto de divulgação científica no ensino de cinética química. Revista Insignare Scientia-RIS, v. 2, n. 1, p. 127-137, 2019. 